\title{
Phenomenological Obviousness and the New Science of Consciousness Justin Sytsma $^{1}$
}

Is phenomenal consciousness a problem for the brain sciences? An increasing number of researchers not only hold that it is, but that its very existence is a deep mystery. That this problematic phenomenon exists is generally taken for granted: It is asserted that phenomenal consciousness is just phenomenologically obvious. In contrast, I hold that there is no such phenomenon and, thus, that it does not pose a problem for the brain sciences. For this denial to be plausible, however, I need to show that phenomenal consciousness is not phenomenologically obvious. That is the goal of this article.

\section{Introduction}

This article is a first step in answering the question of whether phenomenal consciousness should be seen as a problem for the brain sciences. I accept that if there is such a phenomenon, then it does indeed pose a significant problem and we should not fault a growing group of scientists (those involved in what I will refer to as the new science of consciousness) for taking it seriously. But, should we accept the reality of phenomenal consciousness? I hold that this is a non-trivial question that is often trivialized by blunt assertions that phenomenal consciousness is

\footnotetext{
${ }^{1}$ The author would like to thank Edouard Machery, Ken Schaffner, and the audience at the 2008 PSA biennial meeting for their helpful comments.
} 
phenomenologically obvious - that it is manifest in introspection or that everyone knows it from their own experience. In this article I argue that this claim is false: I argue that phenomenal consciousness is not phenomenologically obvious.

To illustrate, consider the opening line in philosopher Daniel Stojar’s (2006, v) recent, well-received volume on the problem of consciousness:

Apart from its phenomenological obviousness, the two central facts about conscious experience are these: It is philosophically puzzling, and we are scientifically ignorant with respect to it.

Stoljar asserts as fact that conscious experience (what I referred to above as phenomenal consciousness) is phenomenologically obvious and that we are scientifically ignorant of it. One reasonable conclusion to draw from these supposed facts is that further scientific work into the phenomenon is warranted. A number of prominent scientists - the new scientists-have drawn exactly that conclusion from philosophical claims like Stoljar's. They typically take the reality of phenomenal consciousness for granted ${ }^{2}$ and seek to offer a scientific explanation of this holdout against the progress of modern science.

In contrast, I assert that we remain scientifically ignorant of phenomenal consciousness because there is no such phenomenon. To make this assertion plausible, however, I need to argue that phenomenal consciousness is not phenomenologically obvious (after all, if Stoljar is correct, then my denial of the phenomenon would seem to be rather misguided). I do this by first arguing that if phenomenal consciousness is in fact phenomenologically obvious, then it should

\footnotetext{
${ }^{2}$ For example, neuroscientist Christof Koch $(2004,7)$ writes: “Given the centrality of subjective feelings to everyday life, it would require extraordinary factual evidence before concluding that qualia and feelings are illusory." This leads him to "consider first-person experiences as brute facts of life" (7). The sentiment that phenomenal consciousness is evident in everyday experience is most often seen in the common claim that everyone knows phenomenal consciousness. For example, psychologist Nicholas Humphrey writes that "each of us in the privacy of our own minds knows what it is" (2006, 3); Nobel Prize winner Francis Crick notes that "in a general way we all know what consciousness is like" (1994, 13); Nobel Prize winner Gerald Edelman says "we all know what consciousness is" (2004, 4); psychologist Jeffrey Gray discusses "the fact that everyone knows it as an empirical fact (in each of our personal lives)" $(2004,6)$.
} 
be obvious to people without training in philosophy or the new science (since they too have the phenomenology); I then present evidence that this is not the case.

Here is how I will proceed. In Section 2, I briefly introduce the new science of consciousness. In Section 3, I outline my argument against the claim that phenomenal consciousness is phenomenologically obvious. In Section 4, I review recent work on the folk psychology of consciousness, finding that the current evidence suggests that ordinary people do not share the philosophical concept of phenomenal consciousness. I support this finding further, in Section 5, by noting that there are reasons to think that most people hold a naïve view of colors that contrasts with the qualia view underlying the new science understanding of phenomenal consciousness.

\section{The New Science of Consciousness}

Over the course of the past quarter century there has been a growing scientific interest in the philosophical problem of consciousness. The resulting new science of consciousness ${ }^{3}$ is ultimately focused on solving what David Chalmers (1996) has termed the "hard problem"—-the problem of explaining phenomenal consciousness. This phenomenon is understood in terms of there being "something it is like" to be in certain mental states (see Nagel 1974), with the something typically being indicated by noting the qualities we are aware of in having an experience. Paradigmatic examples are redness (such as that seen in looking at a ripe tomato)

\footnotetext{
${ }^{3}$ I take this phrase from the scientists themselves. For example, psychologist Max Velmans (1996, xi) writes of "creating a new science of consciousness which attempts to integrate the findings of traditional 'third-person perspective' science with the 'first-person' evidence of human experience.” Or, consider neuropsychologist Bernard Baars's discussion of new sciences: "Ever since the nova scientia of Galileo and Copernicus began the revolutionary rise of modern physics, new sciences have been proclaimed with some regularity. Most of these announcements turn out to be false alarms. But today we actually find ourselves at one of those rare nodal points in the evolution of human understanding: For the first time in the hundred years since William James's Principles of Psychology, serious brain scientists are exploring conscious experience” (1997, vii).
} 
and painfulness (such as that felt in stubbing one's toe). The central question for the new science is to explain how such qualities arise from neural activity in the brain.

Space constraints prevent me from giving a detailed discussion of the new science, here. It is important, however, to illustrate that the above characterization directly reflects how prominent new scientists describe the discipline. Consider the preface to psychologist Jeffrey Gray’s volume, Consciousness: Creeping up on the Hard Problem (2004, vii):

Consciousness has become a very fashionable topic. It wasn’t always so. A paper I wrote in 1971 about what is now called the 'Hard Problem'... received a grand total of two reprint requests. Indeed, at that time, with behaviourism still dominant in psychology and positivism in philosophy, the topic of consciousness was virtually taboo. My 1971 paper questioned the then popular view ('mind-brain identity theory').... To me, alas, this solution was simply a philosophical cop-out from what, in the long run, was bound to become the scientific version of the Hard Problem: how do states of consciousness fit into neuroscience (since they seem to be created by the brain) and into psychology (since they seem to be related to behaviour)?

The long run may now be over. The problem of consciousness has entered science with a bang, celebrated in a spate of recent books by eminent authors (not to mention new scientific associations, new journals and hundreds upon hundreds of articles).

Gray’s statement is characteristic of discussions of the new science in noting that scientists had turned their backs on the problem of consciousness and asserting that a solution would come from scientists reclaiming the project from philosophers.

Gray’s statement is also characteristic in focusing on the hard problem. As Francis Crick and Christof Koch put it $(2003,119)$ : “The most difficult aspect of consciousness is the so-called 'hard problem' of qualia — the redness of red, the painfulness of pain, and so on.” Such qualities mark certain mental states as being phenomenally conscious and the problem that ultimately drives the new science is to explain how these distinctive qualities could arise from the biological activity of brains; this is held to be a truly hard problem, presenting a troubling puzzle for the brain sciences. Koch expresses the problem nicely in his recent volume (2004, 1-2): 
How do the salty taste and crunchy texture of potato chips, the unmistakable smell of dogs after they have been in the rain, or the feeling of hanging on tiny fingerholds on a cliff a couple of meters above the last secure foothold, emerge from networks of neurons? These sensory qualities, the building blocks of conscious experience, have traditionally been called qualia. The puzzle is, how can a physical system have qualia?

This statement is representative of the new science understanding of phenomenal consciousness. The focus is on the qualities that we are aware of in having experiences like eating a chip or smelling a dog; the qualities are taken to be qualities of mental states and the goal is to explain how they could possibly be produced by the physical brain.

The result is a concept that unites a diverse range of qualities under a single header. Specific tastes, textures, smells, and so on, are taken to have something in common—they are all qualia and they mark the corresponding mental states as being phenomenally conscious. This understanding is also common in the philosophical literature. Non-controversially phenomenal consciousness is taken to cover a diversity of mental states, including perceptual experiences (seeing red, hearing a C\#), bodily sensations (feeling pain, nausea), and felt emotions (happiness, depression; see, for example, Levin 1998, Tye 2003). For each of these mental states there is thought to be something it is like to be in it and this is typically taken to contrast with states like beliefs and desires that lack such qualities.

\section{Phenomenal Consciousness and Phenomenological Obviousness}

It is in this context of a science aimed at explaining qualia that I am considering the claim that phenomenal consciousness is phenomenologically obvious. Specifically, I am concerned with this claim insofar as it is given as justification for the existence of phenomenal consciousness as it is understood in the new science. Further, for reasons of space, I cannot here deal with other types of argument that could be given for the reality of this phenomenon (but, see Sytsma in 
preparation). As such, the claim that phenomenal consciousness is phenomenologically obvious should be understood in a way that directly justifies belief in this problematic phenomenon without undue reliance on unstated and potentially controversial theoretical assumptions (ast these would lead us to a rather different type of argument and take us beyond the scope of the present article). The claim does this if we take it at face value: Many hold that phenomenal consciousness is evident just in having experiences like tasting a potato chip or smelling a wet dog. In effect, the claim is that phenomenal consciousness is observed in such experiences and, therefore, cannot be reasonably doubted. This has a great deal of force exactly because it appeals to what is evident in common experiences and not to theoretical assumptions learned through training in philosophy or the new science. ${ }^{4}$

Note, however, that it is not enough that the salty taste of a potato chip or the stinky smell of a wet dog be obvious. The issue is whether phenomenal consciousness is phenomenologically obvious and the concept of phenomenal consciousness in the new science involves the classification of mental states based on their having (or lacking) qualia. The key point is that these qualities are taken to be qualities of phenomenally conscious mental states. As such, for phenomenal consciousness to be phenomenologically obvious is for it to be obvious from the phenomenology that qualities like the salty taste and the stinky smell noted by Koch are qualities of mental states.

Understood in this way, is it true that phenomenal consciousness is phenomenologically obvious? Certainly many philosophers and new scientists hold that it is. Note, however, that they also have training in philosophy or the new science and that it could be the case that they

\footnotetext{
${ }^{4}$ Let me make clear that my claim is not that calling on theoretical assumptions is generally problematic, nor am I suggesting that theoretical assumptions cannot reasonably be called on in arguing for the existence of a phenomenon; rather, I hold that the force of this particular argument for the existence of phenomenal consciousness (that it is phenomenologically obvious) rests on avoiding appeal to theoretical assumptions.
} 
are calling on theoretical assumptions in this assessment. A better test is to consider the views of people who have the phenomenology but lack the theoretical training. Do ordinary people also have the (perhaps implicit) concept of phenomenal consciousness? If it is true that phenomenal consciousness is phenomenologically obvious, then we should expect that they do; we should expect that the concept of phenomenal consciousness is part of what Dan Dennett has called the folk theory of consciousness $(2005,26)$. Fortunately, assessing this claim about the folk has been the focus of recent work in experimental philosophy and psychology.

\section{Folk Psychology and Phenomenal Consciousness}

Cognitive science has made great progress over the past several decades in expanding our knowledge of how people come to understand psychological phenomena. This understanding is thought to be underpinned by a general cognitive framework-folk psychology or folk theory of mind (Nichols and Stich 2003, Goldman 2006, Malle 2004). This framework is typically called on in explaining our ability to predict behavior, including our ability to conceptualize and reason about mental states such as beliefs and desires. As such, the research on folk psychology has not cast much light on the folk understanding of mental states like seeing red and feeling pain. This has begun to change over the last few years, however, with a wave of fascinating work on the topic being done by experimental psychologists and philosophers (Gray et al. 2007; Knobe and Prinz 2008; Sytsma and Machery 2009, under review; Arico under review; Arico et al. under review; Huebner ms).

Of particular interest is Joshua Knobe and Jesse Prinz’s (2008) pioneering work presenting empirical evidence that the folk understanding of these states corresponds with the philosophical concept of phenomenal consciousness. Most notably, in their second study they 
asked subjects to evaluate how natural it is to ascribe a range of mental states to a group agent (Acme Corporation). Knobe and Prinz found that the folk seem to be unwilling to ascribe those states that philosophers take to be phenomenally conscious (such as feeling depressed) to the corporation, while being disposed to ascribe non-phenomenal mental states to it. They interpret these results as indicating that the folk have the (perhaps implicit) concept of phenomenal consciousness, distinguishing between phenomenally conscious mental states and mental states that are not phenomenally conscious.

If Knobe and Prinz are correct, then this would be strong evidence that phenomenal consciousness is in fact phenomenologically obvious, with non-philosophers spontaneously drawing the same distinctions between these mental states that philosophers do. These conclusions have been brought into question, however (Arico under review, Sytsma and Machery 2009). In particular, Edouard Machery and I have challenged the conclusion that the folk posses the concept of phenomenal consciousness. We argue that there is a confound inherent in Knobe and Prinz's approach: Corporations differ in some significant behavioral and functional ways from individuals. A group agent like Acme Corporation is distributed; it does not have an individual body, although it is comprised of such bodies. As such, Acme cannot smile in happiness or grimace in disgust. It is thus difficult to determine whether people focus on the supposed phenomenality of joy or pain (and not on the functional and behavioral differences between distributed corporations and humans) when they deny that Acme can experience great joy or feel excruciating pain. Because of this, we found that Knobe and Prinz's study of the ascription of mental states to corporations does not establish that the folk share the concept of phenomenal consciousness. 
In fact, in a subsequent study Machery and I (Sytsma and Machery under review) produced evidence that the folk do not share this concept. In that paper we reasoned that if the folk share the concept of phenomenal consciousness discussed above, then they should treat paradigmatic examples of phenomenally conscious mental states similarly. Specifically, both the folk and philosophers should deny that an entity that lacks phenomenal consciousness can either see red or feel pain (for example, tending to deny both to a simple robot).

Our first study tested this hypothesis. The study was conducted online with participants (both non-philosophers and philosophers) being given either a description of a relatively simple, non-humanoid robot or a normal human performing behaviorally analogous tasks expected to elicit ascriptions of either a perceptual experience or a bodily sensation in humans. In each scenario the agent (robot or human) manipulated a red box. In half of the scenarios, the manipulation was successful and participants were asked whether the agent "saw red" on a 7point scale anchored at 1 with "clearly no," at 4 with "not sure," and at 7 with "clearly yes.” In the other half, the agent was electrically shocked and participants were asked whether the agent "felt pain" on the same scale.

With respect to the philosophers surveyed, the results of this study were consistent with the hypothesis (see Figure 1). Philosophers treated feeling pain and seeing red analogously. They were unwilling to ascribe either the perceptual experience of seeing red or the bodily sensation of feeling pain to the robot. By contrast, philosophers were willing to ascribe both states to a normal human male. Contrary to the hypothesis that ordinary people and philosophers understand these states in the same way, however, the folk treated the perceptual state of seeing red quite differently from the bodily sensation of feeling pain. Non-philosophers were willing to attribute seeing red to the robot, but were not willing to attribute feeling pain to it. As such, our 
results offer preliminary evidence that the folk do not share the philosophical concept of phenomenal consciousness; they do not treat these states as philosophers do, seemingly failing to recognize that they have something obvious in common (that they are both phenomenally conscious mental states $)^{5}$

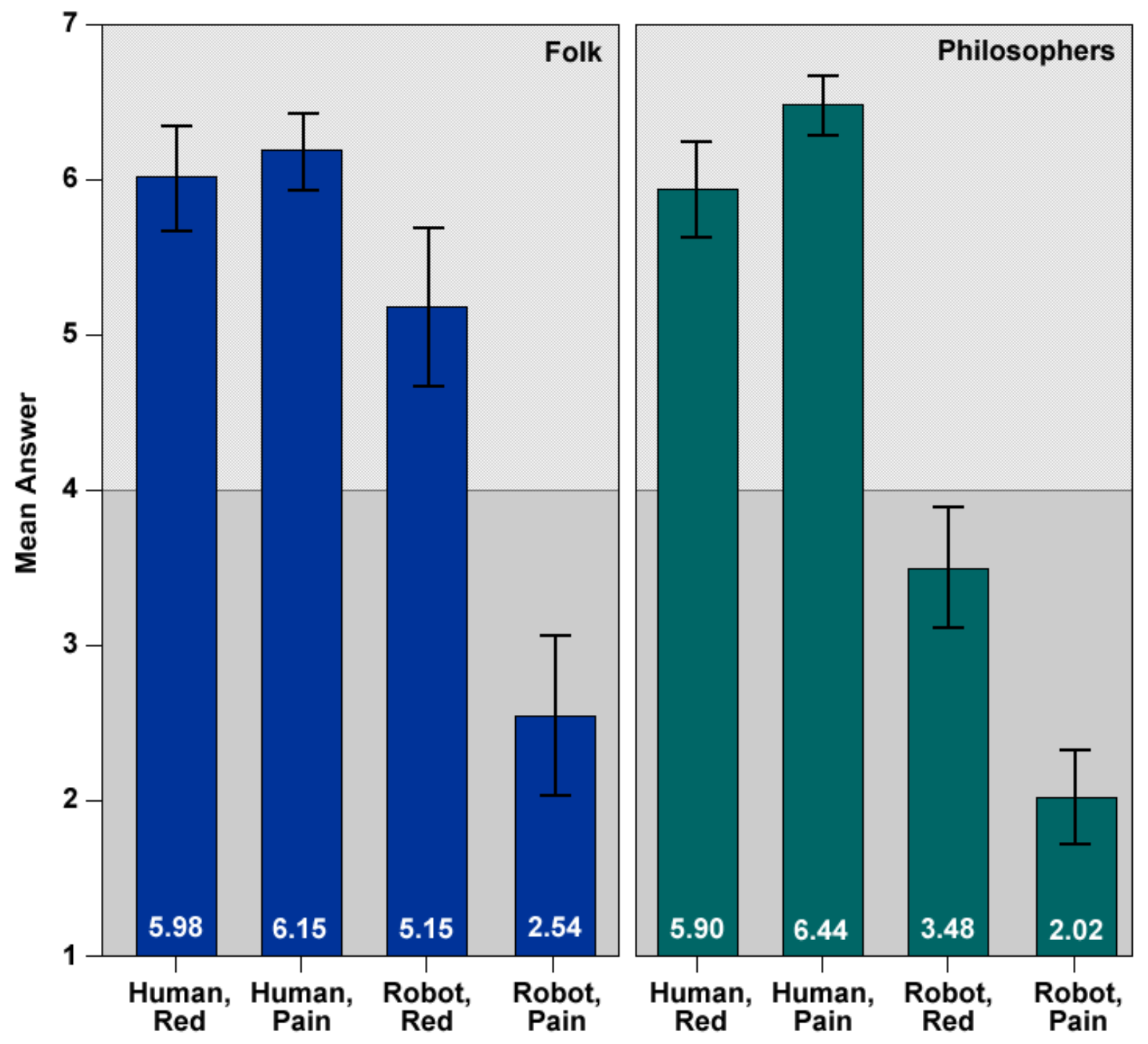

Figure 1: Results, Sytsma and Machery (under review) Study 1 (error bars: 95\% confidence interval).

\footnotetext{
${ }^{5}$ Machery and I go on to investigate the folk understanding of these mental states for its own sake. In two follow-up studies we used a similar method to explore folk views about emotional and olfactory states. Our results suggest that the folk conception of subjective experience is closely linked to a mental state having an associated valence. While these studies also support the claim that the folk conception does not coincide with the philosophical concept of phenomenal consciousness, for the sake of space I just focus on the central cases of colors and pains.
} 


\section{Phenomenal Red and the Naïve View}

The most common objection to my work with Machery discussed in the previous section has centered on the claim that "seeing red" is ambiguous between what we might term an informational reading and a phenomenal reading. The critics of our conclusion tend to hold that on the informational reading a creature sees red if its behavior is responsive to the distinction between those things that we see as being red and those that we do not. In this sense, the simple robot appearing in our probes sees red, as is witnessed by it successfully performing the relevant discrimination task. On the phenomenal reading, however, a creature only sees red if it has the appropriate phenomenal experience of redness. Our critics maintain that the robot does not see red in this sense (because it is not phenomenally conscious). The critics then utilize the distinction between informational and phenomenal seeing to suggest that the folk recognize both readings, but that (for some reason) they focused on the informational reading in responding to our survey questions.

Machery and I offered a number of responses to this ambiguity objection in our original paper, primarily focusing on the distribution of the folk's answers (the answers were not bimodal as would be expected if the folk recognize both an informational and a phenomenal reading) and the folk's explanations of their negative answers (unlike the explanations given by philosophers, the folk's did not indicate a phenomenal reading). Rather than rehash these responses further, however, I want to explore the relationship between the concept of phenomenal consciousness at issue and the view of color that is presumed in the ambiguity objection. I argue that the ambiguity found in the phrase "see red" reflects a theoretical view of color that the folk plausibly lack: The ambiguity primarily attaches to the term "red” (not "see”) and supposes a distinction 
between physical red (red-as-light-reflectance, for example) and phenomenal red (red-asphenomenally-experienced-by-us).

There is a contrasting naïve view of color that does not make this distinction. On this view it is held that colors are real, mind-independent properties of things in the world; as such, the red we experience is taken to be the red of the physical object. The term "naïve” is not used pejoratively; rather, it is used to indicate that there is reason to think that this is the pretheoretical view of colors. As Michael Tye $(2000,147)$ expresses the point: "The obvious view of color, at least as far as common sense goes, is that the color we see objects and surfaces to have are observer-independent properties of those objects and surfaces." If this is correct, then the view that the colors we experience are not qualities of objects, but are instead qualities of our mental states, is rather counterintuitive and stands in need of a motivating argument.

In fact, this view seems to be counterintuitive, in part, because the phenomenology places the colors in the world. As Natika Newton $(2000,63)$ puts it, "visual sensations do not feel like sensations; instead sensations like colour appear to the naïve subject to be properties of external objects." As such, that the color is a "sensation"- that it is a quality of a mental state or a quale - cannot be read off of the phenomenology. But, as discussed in Section 3, the claim that phenomenal consciousness is phenomenologically obvious is best read as asserting exactly the opposite: We are concerned with the claim that qualia are evident in the phenomenology of experiences like seeing red.

That the phenomenology of visual experiences in fact seems to locate colors in the world is rather clear if one considers the responses of those amongst us who are least "tainted" by the prevalent theoretical and scientific views about color (children). As Paul Skokowski $(2007,67)$ notes: "Ask a child where the yellow is when she looks at a daffodil. She will reply 'on the 
daffodil."” The time I have spent discussing colors with children is enough to convince me that our initial understanding of colors, our most purely pretheoretical understanding, treats them as mind-independent properties of worldly objects. Further, I suspect that the pretheoretical view of colors that is found in children remains quite widespread in the general population. ${ }^{6}$ While most Americans today likely come to understand that color is connected to how surfaces differentially reflect light, and perhaps learn that modern science explains colors in this way, this can be accepted without adopting the view that the colors we experience are actually in the mind. That is a non-trivial extension and one that, absent evidence to the contrary, we should not expect that the folk generally make. If this is correct, then it is hardly surprising that the folk would treat "seeing red" differently than many philosophers and new scientists. ${ }^{7}$

\section{Conclusion}

The last two decades has seen a surge in interest in the topic of phenomenal consciousness amongst serious brain scientists. Many hold that phenomenal consciousness poses a distinctively hard problem for the brain sciences and this has motivated the development of a new science of consciousness. This, in turn, motivates philosophical scrutiny of the assumptions underlying this new science. Importantly, we can ask what reason we have to believe that the central explanandum for the new science really exists. In this article I have focused on just one common argument for the existence of phenomenal consciousness: It is often suggested that phenomenal consciousness must exist because it is phenomenologically obvious.

\footnotetext{
${ }^{6}$ As Skokowski goes on to ask (2007, 67-68): "And is it just children who hold such intuitions? Surely there are also many adults who hold identical pre-theoretical, pre-scientific intuitions."

${ }^{7}$ This, of course, rests on the empirical claim that the folk hold a naïve view concerning colors. I have begun to test this claim as part of a larger project assessing assertions that the folk are generally naïve realists. Initial results suggest that most are in fact naïve realists about color, stating that colors are in/on the objects seen, not in the mind, and denying the possibility of an inverted spectrum.
} 
I began by articulating the new science understanding of phenomenal consciousness and unpacking the claim that it is phenomenologically obvious. I argued that if phenomenal consciousness is phenomenologically obvious, then the concept of it should be shared by ordinary people (people without training in philosophy or the new science); it should be part of the folk theory of consciousness. I then discussed evidence suggesting that this bit of philosophical commonsense is mistaken: Ordinary people do not seem to share the concept of phenomenal consciousness. Further, I argued that this in part reflects that the folk (but not philosophers or new scientists) generally hold a naïve view of colors. Colors, whether perceived or not, are held to be qualities of objects beyond the perceiving subject's brain. Taken together, this suggests that phenomenal consciousness is not phenomenologically obvious. My hope is that this goes some way toward clearing the ground for a renewed debate concerning the reality of this supposed phenomenon and the prospects for the science aimed at explaining it. 


\section{REFERENCES}

Arico, Adam (under review), "Folk Psychology, Consciousness, and Context Effects.”

Arico, Adam, Brian Fiala, Robert Goldbert, and Shaun Nichols (under review), “The Folk Psychology of Consciousness.”

Baars, Bernard (1997), In the Theater of Consciousness: The Workspace of the Mind. Oxford: Oxford University Press.

Chalmers, David (1996), The Conscious Mind. Oxford: Oxford University Press.

Crick, Francis (1994), The Astonishing Hypothesis: The Scientific Search for the Soul. New York: Touchstone.

Crick, Francis, and Christof Koch (2003), “A Framework for Consciousness”, Nature Neuroscience 6(2): 119-126.

Dennett, Daniel (2005), Sweet Dreams. Cambridge: MIT Press.

Edelman, Gerald (2004), Wider than the Sky: The Phenomenal Gift of Consciousness. New Haven: Yale University Press.

Goldman, Alvin (2006), Simulating Minds: The Philosophy, Psychology and Neuroscience of Mindreading. New York: Oxford University Press.

Gray, Heather, Kurt Gray, and Daniel Wegner (2007), “Dimensions of Mind Perception”, Science 619: 315.

Gray, Jeffrey (2004), Consciousness: Creeping up on the Hard Problem. Oxford: Oxford University Press.

Huebner, Bryce (ms), “Commonsense Concepts of Phenomenal Consciousness: Does Anyone care about Functional Zombies?”

Humphrey, Nicholas (2006), Seeing Red: A Study in Consciousness. Cambridge: Harvard University Press.

Knobe, Joshua, and Jesse Prinz (2008), "Intuitions about Consciousness: Experimental Studies", Phenomenology and the Cognitive Sciences 7: 67-85.

Koch, Christof (2004), The Quest for Consciousness: A Neurobiological Approach. Englewood, CO: Roberts \& Company. 
Levin, Janet (1998), “Qualia”, in E. Craig (ed.), Routledge Encyclopedia of Philosophy. London: Routledge. Retrieved July 4, 2007, http://www.rep.routledge.com/article/V029

Malle, Bertram (2004), How the Mind Explains Behavior: Folk Explanations, Meaning, and Social Interaction. Cambridge: MIT Press.

Nagel, Thomas (1974), "What is it Like to be a Bat?”, The Philosophical Review 83(4): 435-450.

Newton, Natika (2000), “Humphrey’s Solution”, Journal of Consciousness Studies 7(4): 62-66

Nichols, Shaun, and Sephen Stich (2003), Mindreading. Oxford: Oxford University Press.

Skokowski, Paul (2007), “Is the Pain in Jane Felt Mainly in Her Brain?”, The Harvard Review of Philosophy 15: 58-71.

Stoljar, Daniel (2006), Ignorance and Imagination: The Epistemic Origin of the Problem of Consciousness. Oxford: Oxford University Press.

Sytsma, Justin (in preparation), Phenomenal Consciousness as Scientific Phenomenon? A Critical Investigation of the New Science of Consciousness. Ph.D. Dissertation. Pittsburgh, PA: University of Pittsburgh.

Sytsma, Justin, and Edouard Machery (2009), “How to study Folk Intuitions about Phenomenal Consciousness”, Philosophical Psychology 22(1): 21-35.

— (under review), “Two Conceptions of Subjective Experience.”

Tye, Michael (2000), Consciousness, Color, and Content. Cambridge: MIT Press.

- (2003), “Qualia”, in E. N. Zalta (ed.), The Stanford Encyclopedia of Philosophy.

Retrieved July 04, 2007, http://plato.stanford.edu/entries/qualia/

Velmans, Max (1996), The Science of Consciousness: Psychological, Neuropsychological, and Clinical Reviews. New York: Routledge. 